\title{
Examples of Application of Principle of Superposition in the Design of Structural Systems and in Static Analyses
}

\author{
Janusz Rębielak \\ Tadeusz Kościuszko Cracow University of Technology, ul. Warszawska 24, 31-155 Kraków, Poland.
}

Received: January 02, 2015 / Accepted: January 31, 2015 / Published: April 25, 2015.

\begin{abstract}
The paper presents general description of combined structural system and initial analysis of an innovative system proposed as the main support structure for tall or heavy loaded buildings located on subsoil of very small load-carrying ability or in earthquake areas. Moreover there is presented also an innovative two-stage method of the approximate calculation of the statically indeterminate trusses. Both are invented by the author by application of the principles of the superposition method.
\end{abstract}

Key words: Principle of superposition, foundation structure, tall building structure, static indeterminate truss, computational method.

\section{Introduction}

The initial structural analysis of a complex structural system or comprehensive calculations of such a system may be carried out easy and fast when shape of the structural system will be appropriately simplified and/or the calculation method can give results within the assumed and accepted range of approximation. Patterns of complex structures can be precisely reproduced by suitable replication of the selected shape of a simple modular unit. The same can be done regarding the complex computation procedure, which can be simplified to the series of easy computation stages. In all these cases the principle of superposition method can be suitably applied with very good results.

\section{General Description and Initial Static} Analysis of the Combined Foundation and the Combined Structural System Proposed for Tall Buildings

The tall or heavily loaded building has to be located

Corresponding author: Janusz Rębielak, D.Sc., PhD., professor, research fields: architecture, numerical methods of shaping and design of the space structures, methods of static calculation, lightweight structures for large span roofs, tall buildings, foundation systems. E-mail: j.rebielak@wp.pl. on solid and secure foundation. If the building is placed on a subsoil of small load carrying ability or it is situated in an earthquake area then the structural system of its foundation plays crucial role for the stability of the whole object $[1,2,3]$. In these cases the possible big length or surface of the foundation may be preferable but this requirement is difficult to fulfill taking into account the basic rules of the theory of structures $[4,5,6]$. The main inspirations during the design process of the proposed foundation structure were a shape of the root system of one of the deciduous tree species together with the pattern of stress trajectories in the free-ends beam [7,8]. Basic schemes of an example of the structural configuration of the proposed foundation system are presented in Fig. 1. A model shape of such a structure consists of two simple parallel beams (1) put on a common horizontal slab (2) and connected together by means of additional distance marking elements (3). In the narrow space between both beams there are situated two types of subsystems creating the one common system of the intermediate elements. The short strut $\mathrm{AB}$ is an integral part of this system, it has the theoretically possibility to move only along the vertical direction and it takes forces coming from the 
upper part of a building. The first type of subsystem consists of straight struts located along segments of a broken curve having the convexity directed up, see Fig. 1a. In these members are acting tension forces caused by the vertical force $\mathrm{V}$ and they are connected together by means of theoretically articulated nodes. This first subsystem is supplemented by means of a set of short vertical compression members, which the lower nodes are directly joined to the appropriate main nodes of the foundation. These main nodes are uniformly arranged along the neutral axes of the main beams (1). The second type of subsystem is built by means of struts running along broken curves having the convexity directed down, see Fig. $1 b$.

It is also supplemented by a set of short vertical struts, which in this case are the tension members. Upper nodes of the short vertical members are jointed, like previously, to the main nodes of the foundation system. Due to suitable application of basic principle of the superposition these both subsystems have to be combined together and in this way they build the integrated system of the intermediate elements (4), see Fig. 1c. The main beams will be built as reinforced concrete elements while components of the intermediate system can be made as steel members or also as reinforced concrete members. The arrangement of the component members inside the intermediate system resembles, to some degree, one of the typical forms of a lenticular girder. If the patterns of both of the subsystems are symmetric towards the neutral axes of the main beams (1) then the horizontal reaction components in the boundary nodes, e.g. $\mathrm{H}_{1 \mathrm{k}}$ and $\mathrm{H}_{2 \mathrm{k}}$, are of the same values but they are directed oppositely. It implies that after the integration of both subsystems the resultant horizontal reactions in boundary nodes will be theoretically equal to zero. Due to this structural shape the vertical load force $\mathrm{V}$ can be, in a quite uniform way, distributed along the neutral axes of the main beams (1). It means that the horizontal dimensions of such a type of foundation can be considerably big, which implies, that the value of the
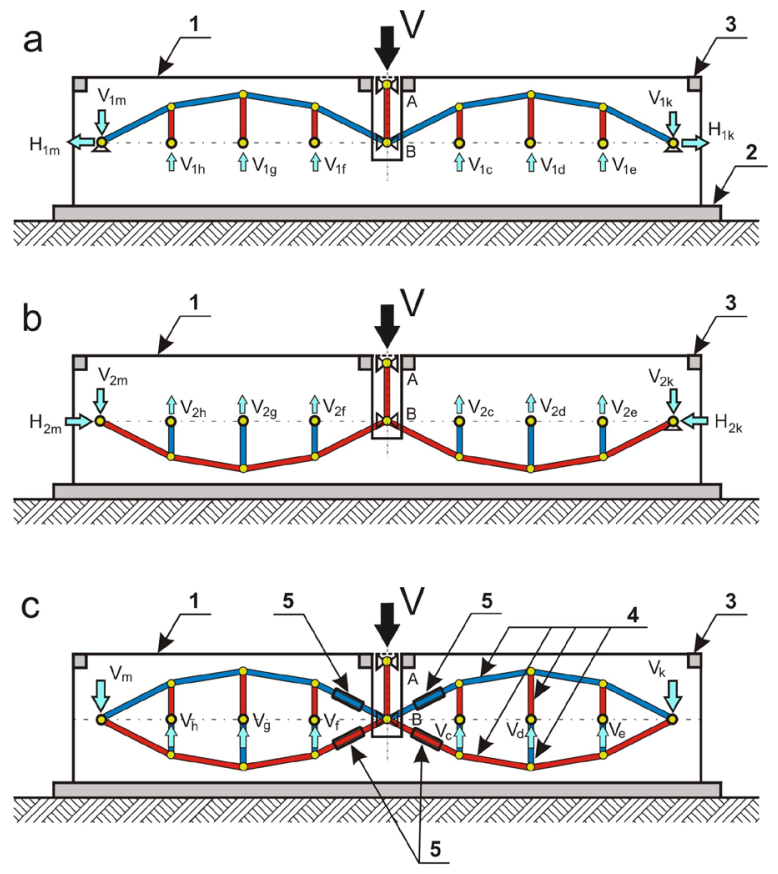

d

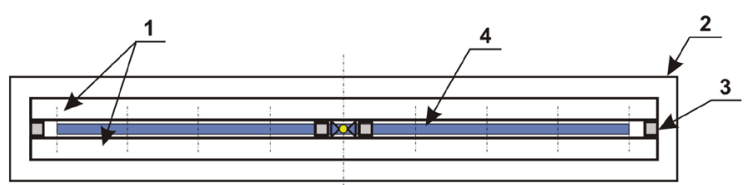

Fig. 1 Schemes of basic structural configurations of the proposed system of combined foundation.

stresses in the subsoil beneath this foundation can be really very small. When the horizontal area of the foundation is large then a sudden, casual and even large translocations of the subsoil will have a relatively small impact on the stability of the structural system of the foundation and of the whole building. Moreover selected members of the intermediate system can be supplemented by means of, for example, hydraulic jacks (5). These technical devices can be suitably controlled by the appropriate computer software and they can serve as specific shock absorbers, which can safely take a significant part of the dangerous vibrations caused by the earthquake. The mentioned hydraulic, or other type of jacks, can be laid out in various ways and they may be located in different structural members.

The vertical structural system of tall building has to be characterized at the same time by two contradictory features; it has to be very rigid but on the other hand it 


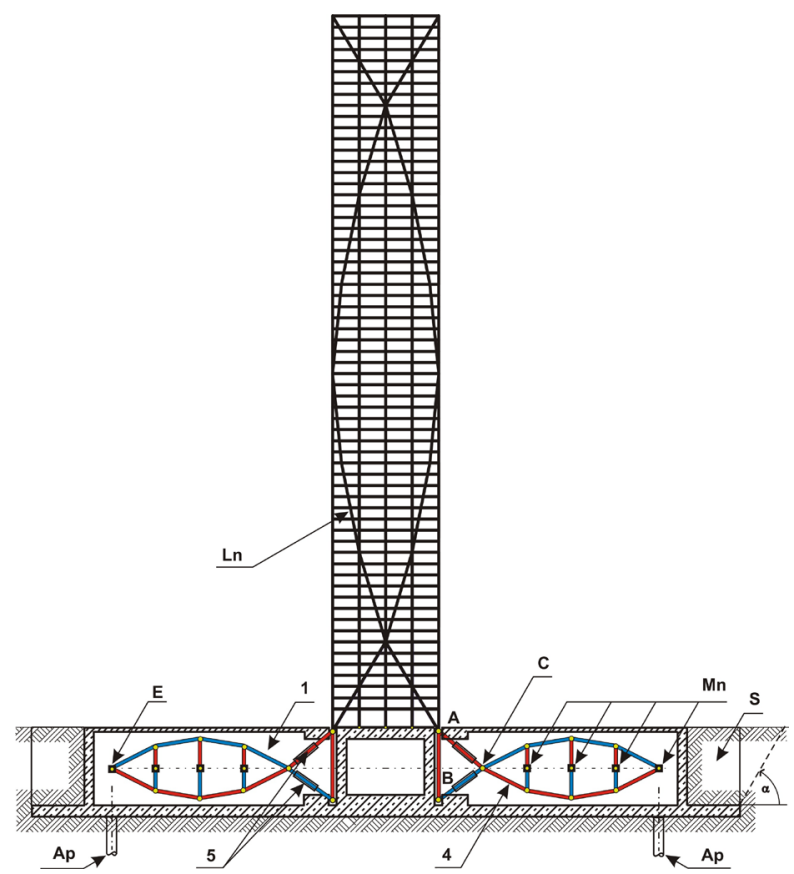

Fig. 2 Scheme of vertical cross-section of a tall building designed by means of the combined structural system.

should be to some degree flexible. If a lenticular form (Ln) appears also in the scheme of the bearing structure of the aboveground storeys then the structural system of the whole building is called the combined structural system of the tall building, see Fig. 2.

Basic form of the lenticular intermediate system is of sufficient structural stability but it can be enhanced by the addition of a certain number of cross braces in the way presented for instance in Fig. 3. The boundary zones of the foundation can be stabilized also by suitable application of anchor piles (Ap).

Axes of these additional cross braces have to meet at the central nodes $(\mathrm{Cn})$ located in the middle of each of the single lenticular elements. The elements of the

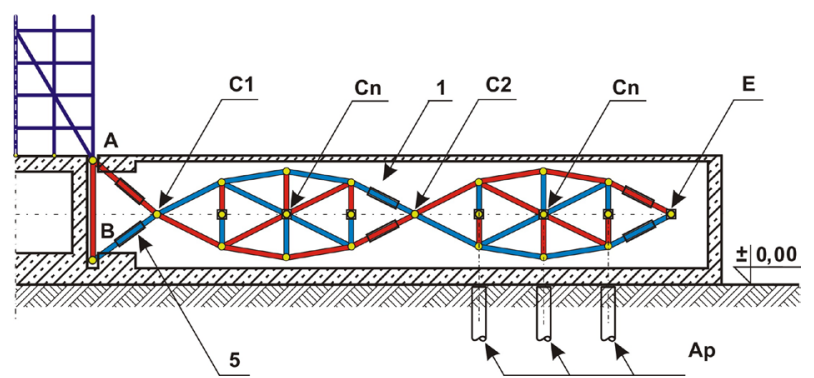

Fig. 3 Example of elongated form of foundation composed of the two modular intermediate elements having additional cross braces. intermediate system may constitute a modular structural unit, which can be replicated along the horizontal direction. These modular units have to be connected together by means of nodes of type $\mathrm{C}$, which in Fig. 3 are represented by node $\mathrm{C} 1$ and node C2. The nodes are not connected to the matter of the main beams (1) and due this feature they can transmit forces to the adjacent segments. It is obvious that number of replication of the basic unit is optional, what further implies, that the surface of this type of foundation system is theoretically unlimited. In case of an even number of replications in the edge node (E) acts the vertical resultant of the reaction typically directed up. Because to the main nodes of every second lenticular element there are applied reactions directed down, therefore below them may be arranged anchor plies (Ap), or for example, inside selected parts of the foundation space there can be distributed some appropriate weights and they can suitably be used for stabilization of the foundation. The structural features of the combined foundation make possible to put even a very heavily loaded building almost on the surface of the ground level without the theoretical necessity of making even shallow trenches. It can be considered as an advantageous feature especially for objects located in the earthquake areas or placed in the mining damaged sectors. In these cases it is recommended to make a horizontal dilatation between the subsoil and lower surface of the foundation slab structure.

\section{The Two-Stage Method of Approximate Calculation of Statically Indeterminate Trusses}

Concept of the two-stage method was initially presented in works $[9,10]$ and then it is widely published in papers $[11,12,13,14]$. The point of this method is an appropriate application, in two stages, one of the simple methods, like e.g. the Cremona's method or Ritter's method, in processes of calculation of the statically indeterminate trusses. Because the Cremona's or Ritter's methods are used for 
calculation of the force values only in the statically determinate trusses, therefore from the basic truss has to be removed, in each of both stages, the number of members equal to the degree of the statically indeterminacy. The reduced trusses have to be of the same clear spans but they have to be loaded by forces of half values applied to nodes of the same positions, like for instance it is shown in Fig. 4.

Taking into account rules of calculus of vectors, the basic conditions of equilibrium and principles of superposition the final results in this two-stage method are obtained as resultants of the force values calculated in each stage for every particular member of the basic truss. The proposed method is applied to determine the force values of the statically indeterminate truss of the scheme shown in Fig. 5.

The considered truss is created by number of nodes " $w$ " equals 32 and the number of members " $p$ " equal to 71. Condition of the inner statically determinacy:

$$
\mathrm{p}=2 \mathrm{x} \mathrm{w}-3
$$

defines, that the plane truss consisting of $\mathrm{w}=32$ nodes has to be built by means of the following number of members

$$
61=2 \times 32-3
$$

It implies, that the truss shown in Fig. 5 is the

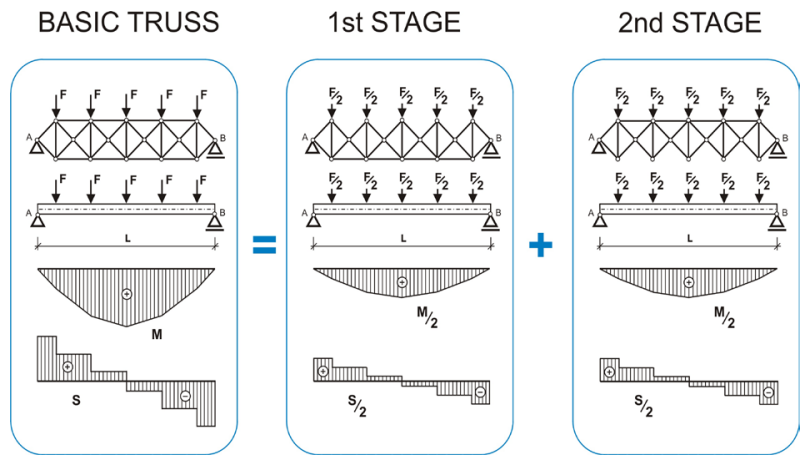

Fig. 4 Schemes of two stages of the proposed method of calculation.

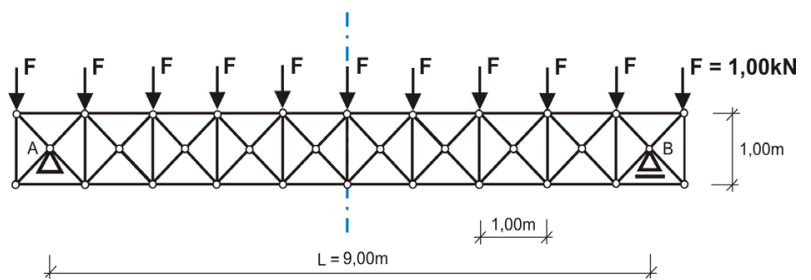

Fig. 5 Selected form of statically indeterminate truss. ten-fold statically indeterminate system. Therefore in the first stage of the proposed method ten members of the upper chord have to be rejected in order to make this truss a statically determinate system. Because the basic truss has symmetric shape and it is symmetrically loaded therefore process of calculations can be carried out only for its half. Results of the first stage of calculations, obtained by application of the Cremona's method, are shown in Fig. 6. In this stage there were removed members of the upper chord from the basic truss. Members of the lower chord are removed from the lower chord of this basic system in the second stage. Results obtained in the second stage of these calculations, also by application of the Cremona's method, are presented in Fig. 7. In both the stages the load forces of half value are applied to nodes of the same positions like in the basic truss.

Final results of values of forces calculated in members of symmetric half of the basic truss by

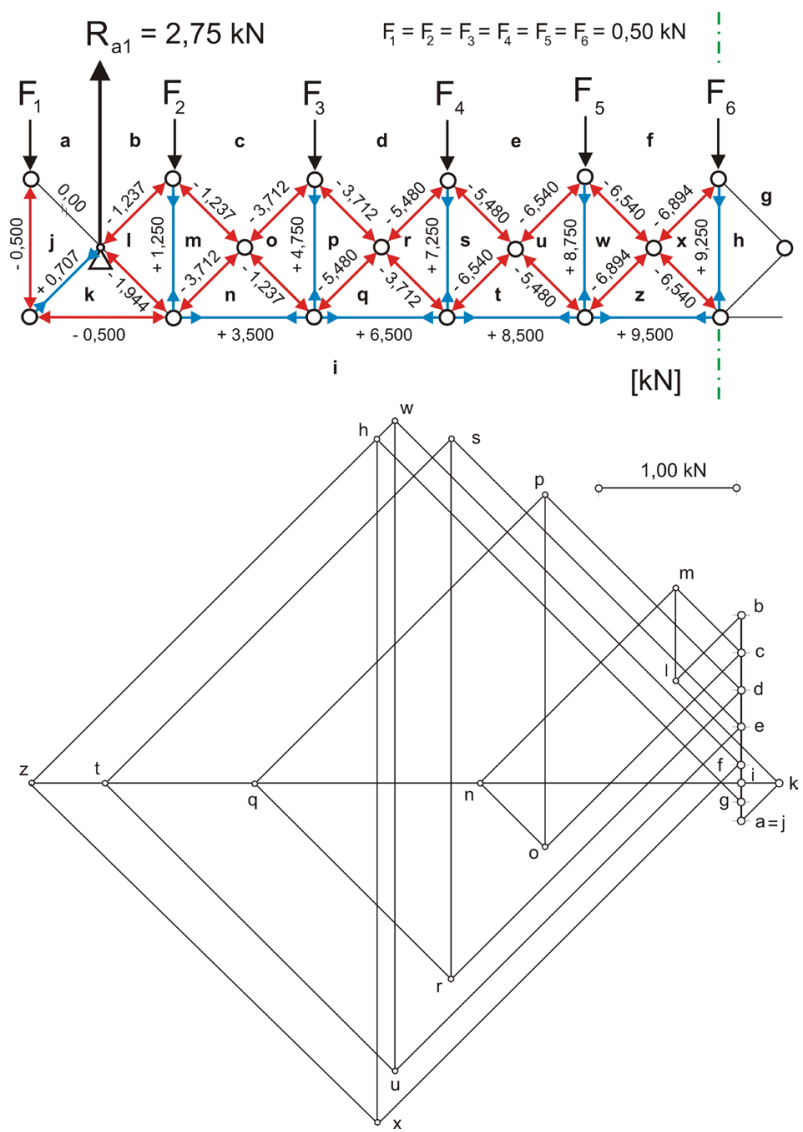

Fig. 6 Values of forces calculated in the first stage of the proposed two-stage method. 


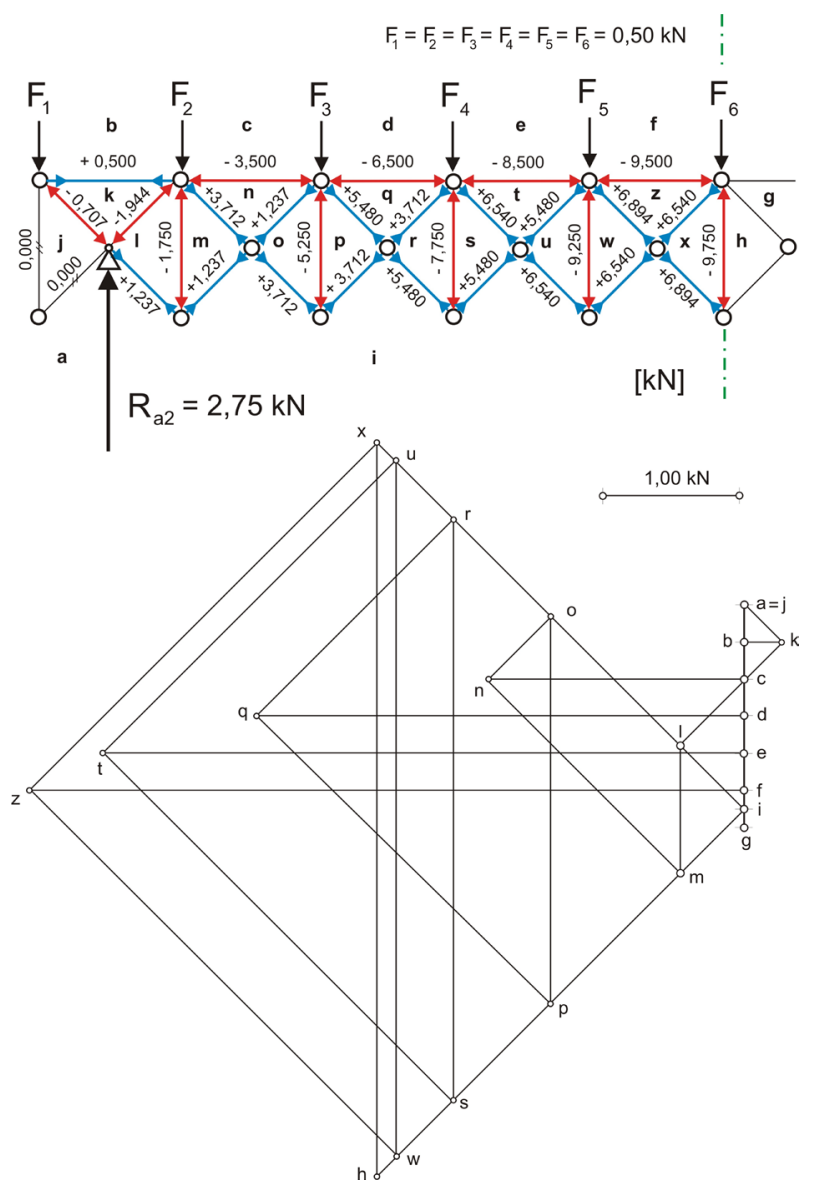

Fig. 7 Values of forces calculated in the second stage.
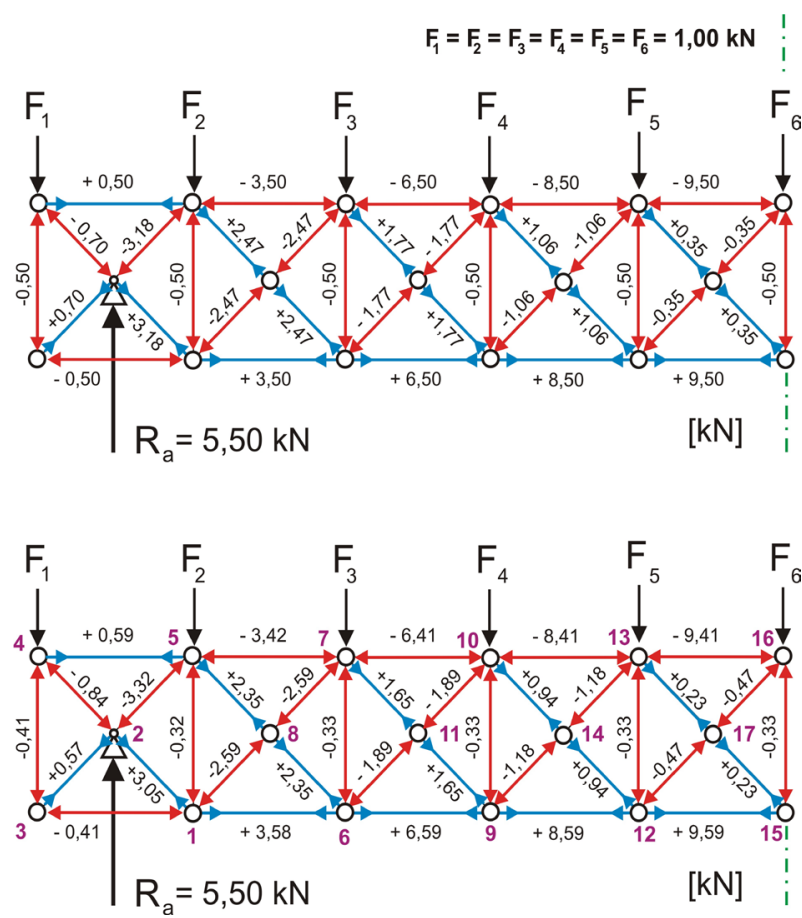

Fig. 8 Values of forces obtained in two different methods of calculations. means of the-two stage method are shown in Fig. 8a Values of forces obtained in both stages for each particular member have to be suitably sum up according to rules of the calculus of forces and the principle of superposition. For example the final force value $-3,18 \mathrm{kN}$ acting in the upper inner cross brace joined to the support node $\mathrm{A}$ is a resultant of compression force $-1,237 \mathrm{kN}$ defined in corresponding member during the first stage, compare Fig. 6, and the compression force $-1,9445 \mathrm{kN}$ determined in the second stage, compare Fig. 7. Horizontal member located straight above the support node A was removed in the first stage, that is why in this area of truss the force value equals $0,000 \mathrm{kN}$. In the second stage the mentioned member remains on its position and the force value calculated in this stage is equal to $+0,500 \mathrm{kN}$. Taking into account all the above mentioned rules and principle of superposition the final force value acting in this member is the resultant of both these components and equals $+0,500 \mathrm{kN}$.

The same basic truss, compare Fig. 5, has been calculated by means of a suitable method applied for computer aided calculations of statically indeterminate trusses in order to compare the force values obtained in two different methods. The second computations were carried out by means of Autodesk Robot Structural Analysis Professional 2015, which software, among others, takes into consideration the stiffness differences of members joined in the same truss nodes. It was assumed that the basic truss consists of the steel tube members having diameter of $30 \mathrm{~mm}$, the thickness of section equal to $4 \mathrm{~mm}$, the Young's modulus of the steel material equals $210 \mathrm{GPa}$. In Fig. $8 \mathrm{~b}$ are presented results obtained in these exact calculations for the half of the basic structure. Although the two-stage method does not take into consideration the differences of stiffness of component parts but it gives in result values of forces very close to these, which are calculated by the exact and sophisticated methods. The approximation is very good for the biggest values. For example the force 
value in the upper inner cross brace joined to the support node A determined by the computer software Autodesk Robot equals $-3,32 \mathrm{kN}$. Force value in the same member calculated by application of the two-stage method is equal to $-3,18 \mathrm{kN}$. The difference equals $0,14 \mathrm{kN}$, what constitutes only ca. $4,4 \%$ of the basic value. The relative differences in case of bigger force values are significantly smaller. For forces of very small real values the differences are bigger but cross-sections of members subjected to such forces are usually of larger areas than it follows from the direct static calculation because these members are mostly designed according to the requirements of the building codes. Therefore the two-stage method as the approximate method can be applied for the preliminary static analyses of the statically indeterminate trusses. Its accuracy can be increased after application of suitable sets of special parameters, which will take into account differences between stiffness of the truss members joined in each particular node.

\section{Closing Remarks}

Conclusions coming from analyses of shapes existing in the nature or from basic rules of e.g. the theory of structures, in connection with suitable application of principle of superposition, may lead to design the very effective innovative types of structural systems as well as to invent the new and very simple calculation methods.

\section{References}

[1] R.M. Kowalczyk, R. Sim, M.B. Kilmister (eds.), Structural systems for tall buildings, Council on Tall Buildings and Urban Habitat, McGraw-Hill, New York, 1993.

[2] K. Matso, Lessons from Kobe, Civil Engineering 4 (1995) pp. 42-47.

[3] J. Moehle, Y. Bozorgnia et al., Case studies of the seismic performance of tall buildings designed by alternative means, Report for the Tall Buildings Initiative, PEER Report 5 (2011) Pacific Earthquake Engineering Research Center, College of Engineering, University of California, Berkeley, CSSC Report 11-02.

[4] T. Kolendowicz, Theory of structures for architects - in Polish, Arkady, Warszawa, 1993, pp. 117-141.

[5] J. Przewłócki, J. Górski, Basis of theory of structures - in Polish, Arkady, Warszawa, 2006, pp. 92-103.

[6] E. Allen, W. Zalewski and Boston Structures Group, Form and Forces. Designing efficient, expressive structures, John Wiley \& Sons, Inc., Hoboken, New Jersey, 2010, pp. 143-184.

[7] J. Rębielak, Combined form of structural system proposed for tall buildings, Proceedings of IABSE-IASS Symposium, London, UK, 2011, p. 308.

[8] J. Rębielak: System of combined foundation for tall buildings, Journal of Civil Engineering and Architecture, Vol. 6, No 12, (Serial No 61), pp. 1627-1634, 2012.

[9] J. Rębielak, Two-stage method of calculation of statically indeterminate trusess - in Polish (1985), TH Delft, Afdeling der Bouwkunde, Vakgroep 4, Project No 4.1.2.1.

[10] J. Rębielak, W.J. Beranek, G.J. Hobbelman, Multi-layer space structures. Statically and geometric problems - in Polish, TH Delft, Afdeling der Bouwkunde, Vakgroep 4, UII - 396 (1985); Scientific Rapports of Instiutute of Architecture and Town Planning, Wrocław University of Technology Nr I-1/P-332/1985.

[11] J. Rębielak, Simple method of calculation of statically indeterminate trusses, Proceedings of $5^{\text {th }}$ Asia Pacific Congress on Computational Mechanics \& $4^{\text {th }}$ International Symposium on Computational Mechanics (APCOM2013 \& ISCM2013), Singapore, 2013, Paper ID - 1594.

[12] J. Rębielak, A two-stage method for an approximate calculation of statically indeterminate trusses, Journal of Civil Engineering and Architecture, Volume 8, Number 5, May 2014 (Serial Number 78), pp. 567-572.

[13] J. Rębielak, New simple method of calculation of statically indeterminate trusses, Journal of Mathematics and System Science, 4 (2014), pp. 367-371.

[14] J. Rębielak, Approximate static analyses of selected types of structural systems, Proceedings of $1 \mathrm{st}$ International Conference on Computational Engineering and Science for Safety and Environmental Problems, COMPSAFE 2014, April 13-16, 2014, Sendai, Japan, CD, pp. 448-451. 